\title{
Empirical positivism, an epistemological obstacle in the learning of calculus
}

Pierre Job ${ }^{1}$ and Maggy Schneider ${ }^{2}$

Ladimath

University of Liège

Département de mathématiques, Grande Traverse, 12 (B37), 4000, Liège, Belgium.

\begin{abstract}
$^{3}$
Using Chevallard's anthropological approach to the didactics of mathematics considered as an evolution of Brousseau's theory of didactic situations, we envision calculus' development as an epistemological transition between two types of praxeologies, pragmatic and deductive, a praxeology being an anthropological and epistemological model of knowledge. This allows us to depart ourselves from a form of dichotomy between formal and intuitive aspects of limits where a mathematical activity should finally resort on some formal definition to be rigorous: we give credit to limits being a pragmatic model of magnitudes relying on mental objects. This understanding of limits is used to argue the relevance of empirical positivism, an epistemology held by Belgian students as well as pupils, as an obstacle to learning calculus, and show how it is reinforced by learning institutions as a consequence of their inability to give credit to a pragmatic level of rationality.

Keywords: Calculus, Limit, Epistemological Obstacle, Empirical Positivism, Pragmatic praxeology, Deductive praxeology.
\end{abstract}

\section{Introduction}

Much research has been conducted to understand students' difficulties with calculus' basic concepts such as limit, derivative, etc. (Bezuindenhout 2001, Martinez-Planell 2012, Monaghan 1991, Orton 1983, Zandieh 2000). The attention was mostly put on first-year university students and last-year secondary school students because of a problematic transition between informal and more formal aspects of calculus that often takes place in and between those two institutions.

Among these researches, a particular attention has been paid to limits because of the role it plays as a central concept in calculus (Artigue 2000, Bezuindenhout 2001). Two main trends can be identified in such researches: one focusing on students' concept images and the other focusing on more formal aspects involving the limit definition.

\footnotetext{
${ }^{1}$ pierre.job@ulg.ac.be

2 mschneider@ulg.ac.be

${ }^{3}$ We thank the reviewers and editor-in-chief for their help in the revision process.
} 
The studies based on students' concept images of limits indicate how much they can interfere with formal aspects of limits. Students' concept images of limits are based on dynamic motion as opposed to its static definition (Bagni 2005, Tall 1980, Tall and Vinner 1981, Williams 1991). Limits are considered unreachable (Tall and Schwarzenberger 1978) and/or as a bound (Cornu 1991) and/or as an approximation (Parameswaran 2007). In conjunction with these elements, researches have also demonstrated a strong connection between students' difficulties with limits and difficulties related to concepts such as real numbers, functions and infinity (Parameswaran 2007, Sierpinska 1987).

Researchers also took an interest in trying to understand students dealing with formal aspects of limits and trying to help them (re)build formal definitions of limits (Bloch 2000, Prznioslo 2005, Swinyard 2011) but overall there is less empirical data to rely on than for concept images.

Our research lies in between these two trends. Using Chevallard's anthropological theory of the didactic (Chevallard 1999) we analyse calculus' history to build an epistemological model based on pragmatic and deductive praxeologies. This model is put to use to develop an unusual view of limits, a bridge between concept images and formal aspects: limits are envisioned as pragmatic models of magnitudes considered as mental objects (Freudenthal 1973, p. 63) giving birth to a mathematical activity having its own legitimate level of rationality although different from the standard one underlying formal aspects of limits e.g. "static" definitions using quantifiers.

This model allows us to argue for the usefulness of taking into account an epistemological obstacle called empirical positivism as a grid of interpretation of students' reactions to tasks involving limits whether on their own or in relationship with other concepts such as derivatives, integrals, etc. The scientific value of this epistemological obstacle lies in its ability to encompass and make sense of broader and broader types of mistakes.

Lastly, we will show how Belgian teaching institutions tend to (unwillingly) reinforce the empirical positivism obstacle by not being able to give credit to the pragmatic level of rationality. This will shed new lights into the cultural side of epistemological obstacle pointed out by Radford (1997) as well as renewing Sierpinska's work (1987) who pioneered epistemological obstacles regarding limits, an approach to limits that drew much less attention in recent years.

\section{Theoretical framework}

The primary tool we rely on is the anthropological theory of the didactic (ATD). Given the widespread use of this theory and its international recognition ${ }^{4}$, we only recall the relevant parts of ATD used in this paper by contrasting it with recent researches in the field also making use of ATD (Barbé and al. 2005, Hardy 2009).

\footnotetext{
${ }^{4}$ Chevallard received the Freundenthal Medal in 2009 for the creation and promotion of ATD.
} 
The scale of levels of codetermination (Chevallard 2002) is at the core of ATD. Using it allows us to envision the didactic of calculus from different perspectives. Barbé and al. discuss restrictions on the knowledge actually taught in classrooms imposed by the knowledge to be taught while Hardy contrasts students' and instructors' perceptions of the knowledge to be learned based on a distinction between rules and norms inherited from Institutional Analysis and Development theory (Ostrom 2005) being incorporated into ATD. Our research differs from these two by being located at a different level of the scale which translates into two differences.

We see ATD as an evolution of Brousseau's seminal theory of didactical situations (Brousseau 1998). We extend the concept of a fundamental situation by taking into account the institutional relativity of calculus and of mathematical concepts in general in a much tighter way than Brousseau did, giving birth to a fundamental situation being understood as an epistemological reference model which, in calculus' case, translates into two types of praxeologies (pragmatic and deductive ones) as will be explained in the next section.

This renewed understanding of fundamental situations, freed from the adidactic constraint, allows us to better integrate epistemological obstacles (empirical positivist) and their cultural aspects, as debated by Johsua (1996), Radford (1997) and Sierpinska (1989); thus incorporating approaches relying on epistemological obstacles such as Sierpinska's (1987). This delineates a first important difference: taking into account epistemological obstacles.

Let us recall a praxeology (Chevallard 1999) is a model of (mathematical) knowledge that postulates any activity, including mathematical ones, can be conceptualized as a task, something to do, a technique used to solve it, and a justification of the technique used to solve the task that can be split into a technology and a theory, a theory being a more abstract level of justification than the technology.

The use of technology and theory constitutes a second difference. Whereas Hardy and Barbé and al. point out a disconnect between theory and technology in school praxeologies, we envision technology as a form of justification not entirely subordinated to theory, each belonging to intertwined but epistemologically different praxeologies, pragmatic and deductive, each having their own legitimacy as argued in the next section.

\section{From calculus to analysis}

Based on an historical and epistemological study, we show it is legitimate to consider calculus as a pragmatic praxeology that evolved into a deductive one. The main difference between the two lies in the type of task they address and the type of validation they make use of (technology in pragmatic a praxeology, theory in a deductive one). From now on, the term calculus will be used to refer to the pragmatic aspect of calculus and analysis to the deductive aspect. 


\subsection{Calculus}

Calculus is focused on the fundamental task of computing features of objects (velocities, etc.) using techniques often relying on infinitesimals considerations (Cavalieri's indivisibles) that will subsequently lead to the concepts of integrals, derivatives and limits. A characteristic of these objects is that they haven't been mathematically defined yet but exists anyway as mental objects shared, or believed to be, by some institutions. They are brought into existence outside people's mind by a mechanism of preconstruction, using various materializations they are involved in (notations, linguistic expressions and so on) in a way that eludes any questioning making those objects' existence appear obvious (Chevallard 1991).

Justifications given to techniques developed to address the fundamental task often rely on pragmatic arguments. A technique is validated if the results obtained are in accordance with results derived using other valid techniques that may even belong to other fields of sciences. For instance, early infinitesimals techniques where used based on their accordance with results obtained using arguments of kinematic nature (Edwards 1982, pp. 98-99).

These aspects of calculus outlines what we will call a pragmatic praxeology (Schneider 2008, pp. 68-75), a praxeology whose task is to compute features of objects that haven't been yet formally defined, that exist as mental objects and préconstruits and whose techniques are justified using pragmatic arguments. We will call such kind of validation a technology to contrast with the kind of validation pertaining to the second aspect of calculus, analysis. It is important to note that such a praxeology is far away from today's standards of rigor but cannot be considered non-rigorous for that reason. It is another type of rigor that prevailed for most of calculus' history. Current standards are conventions that could be chosen differently.

As an example, a forerunner of the derivative defined by a limit appears in Fermat's work among others (Edwards 1982, pp; 122-125): it is what we get from suppressing terms in an algebraic expression. The suppressing techniques may differ according to the subject at hand e.g., suppressing common roots in a ratio. The unity lies in the use of linguistic forms such as "as close as we want", "close enough to". The limit appears as a pragmatic model of the derivative.

\subsection{Analysis and the deductive praxeological level}

After centuries of discovery, a new train of thought emerges that intends to give calculus a foundation that would at least equate ancient Greeks' level of rigor, still being considered a reference of the genre. There are many reasons to this change but a prominent one is the emergence of a new concept, that of function. This concept allows mathematicians to formulate problems that originated in physics or geometry in a way independent from them. This conceptual revolution permits mathematicians to envision calculus as a new discipline called analysis on which geometry and physics would rely, inverting its historical genesis. Starting with Euler, geometry and physics are seen as applications of calculus and thus pushed at the end of treatises (Edwards 1982, p. 68-72). For this new foundation to be completed it is necessary to justify 
calculus' arguments on an internal basis, getting rid of pragmatic arguments that were until then the standard practice. This major cleaning isn't done at once. It results from diverse elements that forbid mathematicians to further postpone the study of foundational aspects of their discipline. Among these the followings play an important role.

- Mathematicians have to teach calculus to absolute beginners and therefore have to clarify the subject by writing textbooks.

- The study of functions gives birth to "monsters" showing the limits of kinematic and geometric intuitions.

- Major contradictions arising from an unquestioned use of infinitesimals have to be smoothed away.

- Lagrange's call for the building of a sound basis for calculus had a noticeable impact. He made this question the theme of the then famous Berlin prize that could launch a career.

Various ways of carrying out that goal are considered before limits: mainly infinitesimals (Carnot 1797 ) and power series (Lagrange 1797). None of these are considered sound enough. We have to wait until Cauchy. He is considered by many to be the true creator of analysis and the modern concept of limit even if Weierstrass brought subsequent improvements (Dugac 2003, p. 93). Cauchy's definition is a tool created to support the entire architecture of analysis using for the first time on a large scale the famous so called $\varepsilon-\delta$ technique (Grabiner 2005, p. 115).

The way we have outlined analysis defines a second kind of praxeology we shall call deductive (Schneider 2008, pp. 68-75). This kind of praxeology contrasts with calculus in that the fundamental task at hand is to define the mental objects used in calculus, in the first kind of praxeology and built a deductive theory that would be self-contained with no references to other fields. Often the techniques used in pragmatic praxeology are used in deductive ones as definitions. The definition of integral given by Cauchy is a good example of such a procedure: an approximation procedure is turned into a definition that, in turn, is used to prove theorems about integrals (existence, etc.).

In such praxeologies, the status of a definition can be very different from that in pragmatic ones. In pragmatic praxeologies, a concept is, in the first place, an instrumental model of an object whatever its membership, mathematical or not, which requires some kind of detachment between the model and the modelled objects. In deductive praxeologies a definition is chosen according to its ability to build a deductive architecture which is coherent with fewer concepts that are the most general possible.

The creation of analysis by Cauchy was a crucial moment in the history of calculus, it turned it into analysis, moving from a pragmatic praxeology to a deductive one, and at the same time established the skeleton of calculus courses for generations to come, where one starts with limits and then build others upon. It constitutes a radical twist from the historical development and 
genesis of calculus. We understand with calculus and analysis how much research and didactic are intertwined. The obligation to teach calculus to beginners combined with the need to establish solid foundations to the subject historically led to a didactical inversion (Freudenthal 1961, p.ix).

\section{Empirical positivism, an obstacle in the learning of calculus and analysis}

We illustrate how errors pertaining to calculus and analysis, found among pupils and students, can be interpreted as a by-product of an empirical positivist attitude (EP). The soundness of this approach lies in the ability of this model to encompass, in a coherent framework, broader and broader epistemological obstacles, namely the well-known geometric obstacle of limit (GOL) and the heterogeneity of dimension obstacle (HDO) : GOL $\subset$ HDO $\subset$ EP.

We first explain what empirical positivism is and then provide several examples of the aforementioned genealogy.

According to empiricism, knowledge has its roots in sensory experiences. This philosophy goes against rationalism which asserts knowledge comes from human reason. Following, in the epistemology of sciences, empirical positivism is a position that envisions scientific laws and concepts as an exact reflection of objects found in the "real" world (Fourez 1997, p. 80):

Positivism asserts...we can discover scientific laws independently from any context or project... models, notions and scientific laws exist by themselves and would be an exact copy of the world... physics' laws exists by themselves and are in no way models devised by humans to understand the world that surrounds them.

The empirical positivist attitude allows us to make sense of reactions related to geometric objects or magnitudes defined using limits. The tangent for instance is thought by some pupils as a limit of secants without any topology being defined on lines (Sierpinska 1987). The tangent being for them the primary object, its slope being only a property, a tangent cannot be defined by its slope (Schneider 2008).

Let us move to comparison of magnitudes using "indivisibles" (Schneider 1991). The term indivisible is a reference to Cavalieri's work. He deduces, for instance, the ratio between the volumes of two solids lying between two parallel planes from the constancy of the ratio between the measures of their respective indivisibles e.g. the surfaces obtained by the intersection of the two solids with planes parallels to the aforementioned ones. This comparison is bold because some information about volumes is deduced from another about areas, getting from a dimension to another one. Nevertheless it is valid in this case.

This procedure becomes an obstacle in other cases, for instance when two volumes of revolution are thought to be in the same ratio as the ratio of the generating areas (Figure 1). 


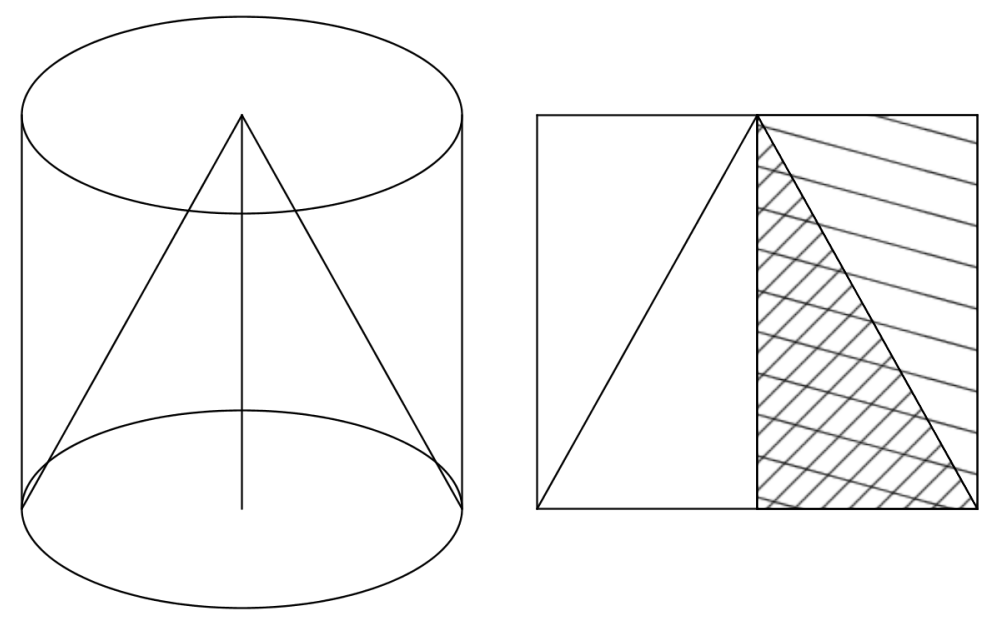

Figure 1

Despite the arguments being given to them, pupils insist the result is correct and argue using magnitudes arguments (solids are made of their radial sections) as if the measures of magnitudes did not exist on their own, measures being only a reflection of what we "see" about magnitudes. This obstacle can thus be seen as a consequence of some sort of empirical positivism. This interpretation translates well to give some meaning to similar errors found not only among pupils but also future teachers (Schneider 1991).

Along the same lines, some pupils doubt a curvilinear area can be exactly matched by a sequence of rectilinear areas because the curvilinear area isn't covered by the rectilinear areas except when they become lines, but then their areas are 0 . Isn't it the same process at work in the $19^{\text {th }}$ century that dictates the erroneous definition of the area of a surface as the limit of the areas of inscribed polyhedral surfaces, a definition Schwartz will stand against using a rather sophisticated argument?

Let us be more specific on this example. With the help of their teacher, pupils, as a prelude to learning the integral concept, approach the measure $m$ of the area under the curve $y=x^{3}$ between 0 and 1 with sums of measures of areas of rectangles

$$
\frac{\left(1-\frac{2}{n}+\frac{1}{n^{2}}\right)}{4}<m<\frac{\left(1+\frac{2}{n}+\frac{1}{n^{2}}\right)}{4}
$$

At this point, most pupils agree that $\frac{1}{4}$ is a good approximation of $m$. Some of them, using limits, even advocate $\frac{1}{4}$ to be the exact value of $m$, because $\frac{\left(1-\frac{2}{n}+\frac{1}{n^{2}}\right)}{4}$ and $\frac{\left(1+\frac{2}{n}+\frac{1}{n^{2}}\right)}{4}$ both have the same limit. On the contrary, other pupils are reluctant to accept such conclusions. They argue that however large $n$ is, the rectangles will never entirely cover the required area. There will always be something left. And when those rectangles become segments they have an area whose measure is 0 . It is therefore impossible to have a sum of these that isn't zero. Pupils have a hard time considering $\frac{1}{4}$ the limit of the two sequences as something outside the realm of areas. They act as if 
the limit process was carried out on geometric objects and not on numbers, the measures of these objects (Schneider 1991).

Some pupils are reluctant to accept the derivative concept will provide an exact value for an instantaneous velocity and other instantaneous rate of change such as an instantaneous flow. Empirical data can be given, taken from recent experimentations, to illustrate this aspect. We only present the part that is relevant to our subject. The reader is invited to refer to Gantois and Schneider (2012) for further details. The engineering is built using Brousseau's theory seen from the angle of ATD. The general context is the following. Pupils are asked (task $T$ ) to algebraically determine when two vehicles driving along a rectilinear path have the same velocity. A milieu ${ }^{5}$ (Brousseau 1998) is designed to promote the development of an infinitesimal technique (technique 3) that enables students to answer this question and which can be interpreted as a forerunner of the derivative concept based on limits. This is done in three main parts. The two first parts, we will not elaborate on, are concerned with connecting movements' characteristics (acceleration, etc.) with their graphical representations' characteristics (concavity, etc.) and designing graphical techniques to answer $T$.

Three techniques arise based on well-chosen didactic variables. An algebraic version of the problem is then presented to the pupils. First they have to deal with $p_{1}(t)=\sqrt{3} t$ and $p_{2}(t)=t^{2}$ then with $p_{1}(t)=\sqrt{3} t$ and $p_{2}(t)=t^{3}$. The first two techniques serve one main purpose. They allow a pragmatic validation of technique 3 , because results obtained on the first pair are in accordance with technique 3 . These first two are ruled out because, unlike technique 3 , they cannot be used to cope with the second pair as they were for the first one. This allows focusing on technique 3 . Technique 3 sums up to finding smaller and smaller intervals where $p_{1}$ and $p_{2}$ have the same mean velocity because, based on continuity assumptions, they should then have the same instantaneous velocity at some point in the interval.

As an illustration, technique 3 leads to investigate the following equality for the first pair, the left hand side being the mean velocity for $p_{1}$ on the interval $[t, \Delta t]$ and the right hand side the mean velocity for $p_{2}$ on the same interval:

$$
\sqrt{3}=\frac{(t+\Delta t)^{2}-t^{2}}{\Delta t}
$$

This equality can be developed into

$$
\sqrt{3}=2 t+\Delta t
$$

Taking $[t, \Delta t]$ to be smaller and smaller, it leads to take $\Delta t=0$ in $\sqrt{3}=2 t+\Delta t$ giving $t=\frac{\sqrt{3}}{2}$. The instantaneous velocity of a given position law $p$ at time $t$ is obtained taking $\Delta t=0$ in

\footnotetext{
${ }^{5}$ A task for which the students know there is a rational to solve it which makes it possible for them not to rely on didactic tricks.
} 


$$
\frac{p(t+\Delta t)-p(t)}{\Delta t}
$$

after all the algebraic simplifications have been carried out. Technique 3 can thus be understood as the limit concept being "caught in the act" serving as a pragmatic model of instantaneous velocity.

Let us look at what happened with the pupils at this stage when they have to deal with technique 3 . They first start by computing mean velocities on numerical intervals hoping to find some interval on which they are equal but doubt they will achieve the desired goal. The algebraic register is then considered based on a harmless question of the experimenter ${ }^{6}$ ("Try to remember... What are you looking for?"). After some time pupils come to the following derivation. They choose to use $t_{1}$ and $t_{2}$ to denote the ends of an interval in which the looked after instant lies. The mean velocity can then be written $\left(t_{2}{ }^{2}-t_{1}{ }^{2}\right) /\left(t_{2}-t_{1}\right)$ which can be simplified in $t_{2}+t_{1}$. It then follows an equation with two variables $t_{2}+t_{1}=\sqrt{3}$ about which the pupils do not feel at ease because they only have "one equation and two unknowns". The idea that one instant is looked after tells the pupils to equate $t_{1}$ and $t_{2}$. The solution is then quickly found by solving the equation $2 t=\sqrt{3}$. Pupils then try to justify their technique to other pupils and the teacher from which they seek approval.

It is interesting to note at the same time their use of infinitesimal techniques and persisting interrogations about their validity ("It looks strange to equate $t_{2}$ and $t_{1}$ "). These questionings about validity and meaning are focused on $\Delta t$ being zero or not. This emphasis can be interpreted in the following manner. $\Delta t$ and $\Delta p$ have a meaning independent of their ratio as it is the case with the mean velocity concept and in the sensory world. There are thus the primary objects on which their attention is focused. The ratio only comes later. As a consequence, the instantaneous velocity isn't envisioned as the limit of a ratio but as a ratio of limits, reminding us of endless debate around Leibniz and Newton's calculus and infinitesimal procedures. The functional link between $\Delta p$ and $\Delta t$ isn't perceived, both are autonomous. The reader is asked to refer to Gantois and Schneider (2012) for more details.

With these excerpts we find interrogations on the pupils' side going in the same direction as those found in Schneider (1992). In this paper, they consider the instantaneous velocity concept to be an extension of the mean velocity concept and thus consider a 0 by 0 ratio to be physically meaningless: "In no time, no volume is poured and we cannot have a flow with no volume " (Schneider 1992, p. 341). They also argue instantaneous velocity "doesn't exist" because it is impossible to compute exactly using observations and measurements e.g. velocity is denied the status of an intellectual concept, it doesn't exist because it cannot be carried out in the "real" world (Schneider 1992)

\footnotetext{
${ }^{6}$ Exp is used to refer to the experimenter, Prof to the teacher of the classroom and other letters such as E1, N1 and so on to pupils.
} 
To conclude instantaneous rates of change are denied any legitimacy by these students and pupils alike because they are thought in reference to the sensory world to which they cannot belong and the fact mathematics are considered to be an extrapolation of this sensory world. Instantaneous rates of change can thus neither belong to physics nor can they to mathematics.

Empirical positivism also acts as an obstacle towards the learning of analysis. In Job (2011) we study the teaching of limits in a deductive praxeology and show how much a deductive approach to this concept is a demanding task for students. To sum up, students are asked to propose definitions of certain behaviour of sequences of real numbers and then prove properties related to this behaviour. Students are mostly unable to make their definitions evolve. They stay stuck with definitions that are "descriptions" of what they see of the studied behaviour. They are not able to envision their definitions as something to be chosen to allow proofs despite the many contradictions pointed out by the teacher. Students see definition as a description of some mental concept they believe every one of them share. They therefore don't understand the rules of the game they are asked to play, feeling they are asked something unnecessary complicated because "everyone agree with the found properties", "nothing has to be proved". Along these lines it should be stressed that the students are placed in some kind of paradox relating the two praxeological levels. On the one hand they question the validity of procedures used to compute the measures of curvilinear areas and on the other hand the same empirical positivist attitude deprives them to understand the fundamental task of a deductive praxeology (building a deductive structure) and why their initial questioning is meaningless in this new framework (the measure of an area is defined by the limit process so the limit process gives without any doubt the measure of that area). From this we understand how important it is for student to be given the opportunity to investigate pragmatic praxeologies as a necessary step to question their epistemological beliefs as well as stepping board to deductive praxeologies.

To further illustrate our point, we give an example, taken from a paper to be published (Job 2014), explaining the relationship entertained by students engaged in a teaching qualification and already having, or soon to have, a degree in mathematics or engineering, with limits and the real numbers. This experiment was conducted by us in two different Belgian universities (Université de Namur, Université de Liège) across several years ${ }^{7}$. Results exposed below have remained consistent through the years. Students where asked the following question:

"When writing $\forall \varepsilon>0:|x-a|<\varepsilon$, should we specify that $\varepsilon$ is very small ?"

For many students, working within the framework of real numbers,

$$
\forall \varepsilon>0:|x-a|<\varepsilon
$$

\footnotetext{
${ }^{7}$ More than 5 years. This experiment is in fact part of a course in the didactic of mathematics we are in charge of and is repeated each year.
} 
means that " $x$ tends towards $a$ but is never equal to $a$ ". So if anything is to be specified, from the student's perspective, it is that $x$ must be different from $a$.

When a proof is given by us that " $x=a$ ", using the density of real numbers, some students keep going in the same direction, insisting that $\varepsilon$ is different from 0 so $x$ cannot be equal to $a$ and/or modifying the above writing as follows:

$$
\forall \varepsilon>0: 0<|x-a|<\varepsilon
$$

Students, soon to become teachers, thus have a hard time understanding basic properties of real numbers, in connection with limits. They envision the above statement as a mere description, using mathematical symbols, of what they see of limits: $x$ takes values closer and closer to $a$, as close as we want. It is interesting to cross these data with two elements. First, in the reference ${ }^{8}$ textbook Espace Math (Adam and Lousberg 2000, p.65), limits are defined likewise:

" $A$ variable $p$ gets closer and closer to the constant real $k$ or $p$ tends to $k$ if and only if the absolute value of the difference between $p$ and $k$ can be made smaller than any strictly positive real number or $|p-k|<\alpha$ where $\alpha$ is a strictly positive real number that can be chosen as we want."

Thus incoherent definitions of limits are also found in reference textbooks. Second, such "definitions" of limits are endorsed by in-service teachers. They see in it the possibility of stripping a more regular definition limits from what they considered too difficult for their pupils, its intertwining between $f(x)$ and $x$. Using the above "definition", they can split a regular definition into two distinct parts that are supposedly easier for the pupils to grasp: the limit of a function $f$ at $a$ is $b$ when $f(x)$ tends to $b$ whenever $x$ tends to $a$. The tends in " $x$ tends to $a$ " and the tends in " $f(x)$ tends to $b$ " are considered meaningful on their own only being connected by an implication ("whenever"). Thus experienced teachers and reference textbooks "behave" like our pre-service teachers. The secondary school system as a whole is blindly teaching incoherent mathematical definitions of limits based on "didactical" considerations. Those definitions again resonates with the empirical positivism obstacle at the level of notations, as already mentioned above, because it once more give credit to notations and pseudo concepts that allow pupils to consider mathematical definitions as mere extrapolations of sensory experiences creating a contradiction. Instantaneous velocity is understood as mean velocity pushed "to the limit". It is thus a ratio. This vision is backed up by the limit definitions found in reference textbooks: instantaneous velocity is a ratio of limits of variables (and not the limit of a ratio). But this understanding of instantaneous velocity is troublesome because a ratio of zero by zero is meaningless in mathematics and has no counterpart in the sensory world.

${ }^{8}$ See below for more details on Espace Math's importance in The French speaking part of Belgium. 


\section{The empirical positivism obstacle reinforced}

In this section, we show how a blurred distinction between the pragmatic and deductive praxeological levels by learning institutions (secondary school and university) tends to reinforce the empirical positivist attitude as an epistemological obstacle to learning calculus and analysis.

We shall review in turn what is going on in secondary school and at university level but let us emphasize first that these results are dealing with the Communauté Française (CF), the Frenchspeaking part of Belgium. This geographical restriction is of importance because CF has its own set of rules (as far as education is involved) and it has a rather small area. We are thus facing a manageable institution in terms of schools and universities. There are only 5 universities which allow an exhaustive review of mathematical courses dealing with calculus (see below for a more accurate description of the studied courses). As for schools they are in greater number than universities, but there is less than 10 reference textbooks in use dealing with the subject of calculus. Of these reference textbooks, one of them, "Espace Math", is an all-time best-seller that is giving us a rather faithful image of what the teaching of calculus look like in CF (others being designed is a very similar way) given more than 20 years of experience in the training of pre and in-service teachers.

\subsection{Secondary school}

In secondary school, the current praxeology related to calculus-analysis belongs neither to the pragmatic level nor the deductive one. It lies in some nowhere land as to the mathematical standpoint. We will therefore call that praxeology a didactic one to contrast with sound mathematical ones. It consists of a mixture of the two praxeological levels that gives birth to a didactic praxeology with "holes" (Rouy 2007, p. 236). That is, a praxeology where the logos part is missing or at least almost irrelevant to the praxis one. Let us give an example focusing on limits but paradigmatic of the teaching of analysis (Job 2011, pp. 197-215).

Secondary school is in a somewhat peculiar situation with respect to mathematics. Its goal is not to produce mathematics but to teach them. The legitimacy of mathematics taught in secondary school is drawn from the institution of mathematicians, an institution teachers encountered during their degree. Those teachers often consider deductive aspects of mathematics and the accompanying idea of "rigor" to be the very essence of the subject to be taught. In our case calculus-analysis gets reduced to analysis. The pragmatic praxeological level of calculus is ignored.

Unfortunately, secondary school fails to teach analysis to pupils in part because of their empirical positivist attitude towards mathematics. Confronted with the obligation of succeeding in teaching mathematics, secondary school has no other choice left than to make its didactic praxeology appear, from an outside perspective, as a valid deductive one, lighter than the one used in analysis by mathematicians but anyway having a logical coherence. To do so, secondary school makes use of enough definitions, results and notations than are considered emblematic of analysis to pretend a meaningful mathematical activity is conducted is the classrooms. Among these blazons, the definition of a limit plays a key role as the central concept of analysis. 
From an inside perspective, the situation looks quite different. Secondary school tries to teach the limit definition using various tricks to make students believe this definition is a somewhat complicated (mathematical) way of saying something very natural. For instance, it gives students tables with values of $x$ and $f(x)$ for a given function, waiting for the students to recognized some sort of behaviour that should be put into sentences like "as $x$ tends to ... $f(x)$ approaches ..." (see Espace Math). Starting from such sentences, teachers gradually turn these into the required forms " $f(x)$ can be made as close as one wishes to ..." using arguments and ranges of graphics that belong more to rhetoric than mathematics. In other words, the very way limits are introduced runs along the lines of empirical positivism: concepts are just a (sometimes complicated) way of saying what everyone can see on a graphic or in a table.

Such an approach is misleading in nature for limits were designed by Cauchy to conduct proofs and define other key concepts of analysis such as the derivative. But except for a few trivial ones, proofs in secondary school are left aside. So the very use of limits in the deductive praxeology (where it belongs) is left aside. The school praxeology thus bears no fundamental character whatsoever.

Such a fool's game isn't the consequence of any malicious thoughts on the side of secondary school but the result of antagonist constraints. On the one hand, it has to teach limits in a way mathematicians would recognize as valid, which is a daunting task. On the other hand it must succeed in that task. The only way secondary school has to its disposal to conciliate the two is to take the deductive praxeology, strip it from most of its content and wrap it in a discourse that can be accepted by pupils even if the cost is to propose tasks that have no fundamental character. This wrapping is partly a consequence of its unawareness of the existence of another praxeology (a pragmatic one) where the limit concept is legitimate. So secondary school's praxeology with respect to limits lies in a no man's land, not being in a deductive or in a pragmatic praxeology. Similar conclusions are drawn in Rouy (2007) regarding the derivative.

This awkward situation tends to reinforce an empiricist positivist attitude among pupils. It is indeed very interesting to note how the derivative concept is taught. Any textbook in Communauté Française de Belgique proceeds along the same lines and this is confirmed by our experience on the field when visiting pre and in-service teachers. The derivative $f^{\prime}(a)$ is introduced as the slope of the tangent $T$ to the graphic of $f$ at $(a, f(a))$. It is then suggested the derivative can be computed by a limit process using graphics where the pupils can see a sequence of lines rotating around a fixed point $(a, f(a))$. The tangent is then "defined" using the derivative which creates a vicious circle. The primary object from which the derivative is "defined" is the tangent which is in turn defined using the derative. The limit involved in the derivative is thus not a concept about numbers but something acting on geometrical objects, graphics and tangents. It is therefore no surprise pupils have a hard time envisioning mathematical concepts from a different perspective 
than sensory perceptions put into symbols, symbols that have to share the same exacts properties as those they "observe" in "concrete" objects: that is exactly how they are taught.

\subsection{University level}

At university level, in CF, in most courses devised for students in mathematics, physics and engineering, the focus is put straightaway on the deductive aspects of praxeologies (e.g. analysis) using axiomatic presentations, but in a much more visible way than in secondary school: you are taught all the definitions and proofs making the deductive architecture of analysis ${ }^{9}$. The reason for this emphasis is obviously different than the one prevailing in secondary school. Teachers at university level are professional mathematicians, the ones who (as an institution) designed analysis. They are thus their own reference and don't have, as long as the scientific side is involved, to pay obedience to anybody except their own institution. This prevalence of deductive aspects and axiomatic presentations is to be linked with empirical positivism and another epistemological attitude, more or less consciously held by professional mathematicians: the Platonic epistemology.

Following Bouveresse (1998, p.1), mathematical Platonism is a philosophical conception which postulates mathematical objects exist independently of our thought activities and knowledge. Mathematical concepts are thus not invented, they are discovered. The discovery is made possible using mathematical intuition. Charles Hermite's words are very exemplary of this epistemology. He deeply believes we simply have to use "the eyes of the mind" to discover new mathematical objects (Dugac 2003, p.197).

Our interest for that philosophy lies both in the fact that according to Davis and Hersch (2012, p. 359), "Most writers on the subject seem to agree that the typical working mathematician is a Platonist" and its connections with mathematical teaching, in particular with empirical positivism related to pragmatic and deductive praxeologies.

Part of the connection between these two epistemologies is rather obvious. The two share the idea that we simply have to observe objects whether they are from the "real" world or from the mathematical world to gain some awareness/insight about them: they are not concepts invented by man to structure their sensations, they both exist in "nature". Hermite further illuminates us as to the connections between Platonism and empirical positivism from a mathematician's perspective. He believes mathematical objects are "more real" than objects from the "real" world. Observing mathematical objects better informs us as to the nature of the "real" world than objects from the "real” world itself (Dugac 2003, p. 197).

For a mathematician holding that kind of epistemology, once a concept has been discovered, teaching that concept mainly sums up to showing it, that is presenting its axiomatic definition and

\footnotetext{
${ }^{9}$ The only noticeable exception is the course given by UC's teacher for first year students in mathematics and physics.
} 
use in various theorems. Either you are able to see what has to be seen because you have the required mathematical insight or you are not. As a consequence there is no real point in paying attention to student's mental objects and concept images, even if they are in contradiction with the mathematical concepts to be taught. The pragmatic praxeological level of calculus is thus left aside and the empirical positivism held by students is never confronted, allowed to survive in some confusing epistemological imbroglio. A student may well be aware of contradictions between his mental objects and the mathematical ones. He will simply get passed the contradiction assuming his constructions are not mathematical. So there is no comparison to be made. This state of affair is closely related to what Chevallard (2005, p.13) denounces when he is speaking about monumentalism: mathematical courses sum up to a museum visit, showing concepts after concepts.

Among axiomatic presentations of analysis in CF, two stand out from the others because they make use of non-standard analysis (NSA). Our aim is to have a look at the way this theory can be used in CF, as a didactic tool to teach analysis, in connection with empirical positivism. This will further illuminate us as to why empirical positivism is reinforced by universities. Having this goal in mind we focus on two different courses designed by A. Pétry on the one hand (Pétry 2010) and J. Bair and V. Henry on the other hand (Bair and Henry 2008). Both have in common the belief that NSA is a formalism that is easier to understand than the standard one, because it is felt by their authors as more "intuitive" and "closer to the way mathematicians and engineers think" (Pétry 2010). Bair and Henry (2006, p.1) explicitly endorse a positivist attitude towards mathematics: NSA is a better way to teach analysis because it is a better extrapolation of the sensory world than the standard formalism is. We are thus confronted with an explicit will to teach along the lines of a positivist epistemology. The adopted formalism feels to us like a trompe l'oeil. Going back to what we previously said, it gives credit to instantaneous velocity understood as a ratio of infinitesimals, depriving students from the opportunity to consider mathematical concepts as not just an extrapolation of sensory experiences (unquestionable "facts" for these authors) but as intellectual constructions whose aim is to structure the world. Considering the highly sophisticated definitions of hyper reals and the likes found in NSA, it is doubtful any first year student would be able to understand these constructions. The problem is eluded by Pétry using a technological metaphor that again goes in the direction of empirical positivism despite the fact he isn't endorsing this epistemology. To him, hyper reals, whether infinitely small or large, can be "seen" on an extended real line using some sort of microscope (Pétry 2010, pp. 40-45). Questions pertaining to infinitesimals' nature are put aside using a visual token allowing students to make use of their sensory perceptions: what you have to understand is what I show you on the board with my microscope.

\section{Conclusion}

The blurred distinction, for learning institutions, whether it is Belgian secondary school or university, between the pragmatic and deductive praxeological levels tends to reinforce an already well-established epistemological attitude among learners, the empirical positivist attitude, as an 
epistemological obstacle towards the learning of calculus and analysis. Such a learning framework allows students and pupils alike to never face their deep unconscious epistemological beliefs about mathematics, beliefs that may survive through an entire degree in mathematics.

As an implication for teaching, it appears interesting to engage students, but not exclusively, into tasks allowing them to develop meaningful (to them) and significant mathematics (from the mathematical point of view), based on mental objects related to calculus (thus belonging to the pragmatic praxeological level of rationality) and then other tasks offering students the possibility to realise the limits and paradoxes of those mental objects and thus the need to develop a new level of rationality, a safer ground on which mathematics can be developed. In a paper to be published (Job 2014), we present and analyse a task designed for secondary school to help pupils lessen the gap between calculus and analysis when they enrol in university following a degree in mathematics.

At the same time, the teachers should be acquainted with enough of calculus' epistemological evolution, in particular the possibility to do some mathematics without an already well-established formal framework e.g. relying on mental objects, to raise some degree of awareness about the importance of the aforementioned tasks. This seems feasible at the school level through pre and inservice teachers' courses but it might be more difficult at the university level when as pointed out for instance by Barquero and al. $(2013$, p.325) we are facing institutional constraints such as a tendency to

"organise its [mathematics] teaching according to the internal logic of concepts (instead of those of problems), eliminate the rationale of the taught mathematical praxeologies, presenting them as 'lifeless monuments' that must be studied without showing its functionality. In addition, all these pre-established answers are supposed to be transparent and not problematic, promoting 'authoritarianism' [which is] reinforced by 'applicationism,',

Our two praxeological levels (pragmatic and deductive) also allow us to look at some researches in the field of calculus with a different eye, asking new questions pertaining to learning and teaching calculus. We shall consider two different questions. This concluding thought may be understood as an echo of what we underlined in the introduction, what we felt was an in-between positioning among other researches.

Let us start with Edwards and Ward (2004). They conclude (p. 419) "the special nature of mathematical definitions should be addressed more directly in mathematics courses at all levels". Our research is in agreement with this conclusion. We nevertheless are more cautious as to their reasoning relying on the distinction (p. 412) between an "extracted" definition "based on examples of actual usage" and a "stipulated" one, an "explicit and self-conscious setting up of the meaningrelation between some word and some object". They believe "mathematical definitions [are] stipulated", whereas most "everyday language" definitions are "extracted" and thus argue failure 
on the students' side to distinguish between "extracted" and "stipulated" definitions "affects their understanding of the concept themselves", they have a tendency to "rely on their concept image instead of the related concept definitions". We are reticent based on the following ground. As we have seen, in pragmatic praxeologies (that is in calculus as we defined it) most definitions can obviously not be considered "stipulated". We should then conclude following these authors that no meaningful mathematical work has been done during the calculus era which is not tenable. Moreover, following Lakatos' seminal work (1976), definitions in deductive praxeologies are often proof-generated as is the case for the limit definition (Burn 2005) and thus have some "extracted" side being the result of an iterative process based on usage, trying to proof a theorem. We thus have to reject the distinction between "extracted" and "stipulated" as a mean to characterize what mathematical definitions are. Finally, mathematical definitions in calculus and analysis have a history that cannot be reduced to their latest evolution, because this latest trend can only be understood in the light of the previous understandings of those definitions. Somehow Edwards and Ward give, at the researchers' level, an example of the blurred distinction between pragmatic and deductive praxeologies, the importance of which we have argued, by not being able to give credit to definitions the way they were used in calculus and its very relevance in the subsequent constitution of analysis. More broadly we ask the question of reconsidering the socalled "misconceptions" of students regarding limits and try to determinate how much of these conceptions can be interpreted not as inherent to the students themselves but as a by-product of teachers and researchers (implicit) epistemologies preventing them from understanding how much the tasks they enrol students in may contribute to create these "misconceptions"?

Let us turn to Prznioslo (2005) and Swinyard (2011). Both propose a type of task (T) designed to make students build their own definition of limit using similar principles. Starting from an initial definition, students are asked to create new ones encompassing more and more examples and "counter-examples" (graphic or analytic) given by either the teacher or other students. For instance a student saying " $\lim _{x \rightarrow a} f(x)=b$ when $f(x)$ gets closer and closer to $b$ as $x$ gets closer to $a$ " could be confronted with the following argument: "according to your definition $|x|$ has -5 as a limit in 0 because $|x|$ is getting closer and closer to -5 as $x$ is getting closer to 0 ".

Distinguishing between pragmatic and deductive praxeologies makes us question the mathematical relevance of $T$.

- $T$ does not fit into pragmatic praxeologies. We are not trying to determine any kind of magnitude.

- $T$ does not fit into deductive praxeologies either. If we look again at the constitution of this last kind of praxeology we recall Cauchy built his definition of limit not to comply with a set $S$ of functions sharing a common feature given beforehand but to be able to prove theorems about derivatives and the likes. The common feature comes afterward as a consequence of the definition. 
If $T$ doesn't fit in a pragmatic nor a deductive praxeology we are then entitled to raise some concerns about its mathematical soundness because these praxeologies make up the epistemological skeleton of calculus and analysis.

Our interrogations are further deepened for at least two reasons.

First, as a sort of side effect, Cauchy's approach to creating definitions and proof-generated definitions in general may lead a definition to encompass objects that would not at first, from a "naïve" point of view, be considered to fall under the scope of that definition. For instance, with Cauchy's definition we are forced to accept the limit of a constant function to be that constant, an incorporation which is felt by more than one student as unsound (Antibi 1988, pp. 183-185). So if we want to play $T$ with $S$ including constant functions we are likely to get into trouble. It means in general terms $S$ should be filled only with limits of functions that do not interfere too much with students' concept image which isn't likely to help them making a transition towards deductive reasoning?

Second, we may contrast $T$ with deductive praxeologies from another point of view. In deductive praxeologies you have, at least in principle, a rather clear termination criterion: your definition is good enough when it allows you to prove the theorem you want to prove. Using $T$ the termination criterion becomes rather loose. The iterative process of building a definition ends when either the teacher or the students are not able to propose new "counter-examples". And when we reach that ending step we haven't proved anything yet. Thus what have we done? Taking a step back, we feel $T$ is a rather elaborate kind of ostension (Brousseau 1998, p.46): with $T$ students are asked to, even if it is disguised under sophisticated guise looking like a proof and refutation game, to build the definition the teacher wants them to build and not the definition required by an "outside" relevant mathematical problem.

Based on these two reasons we are asking our second question: how sound are researches claiming they have been able to make students built the conventional limit definition, what mathematical and epistemological value do the tasks they rely on have?

As a last interrogation, it would be most interesting to determine if our conclusions hold in other countries and if not why.

\section{References}

Adam, A., \& Lousberg, F. (2000). Espace Math 56, Livre de l'élève. De Boeck-Wesmael.

Antibi, A. (1988). Étude sur l'enseignement de méthodes de démonstration. Enseignement de la notion de limite: réflexions, propositions. Thèse de doctorat: Université Paul Sabatier.

Artigue, M. (2000). Teaching and learning calculus: What can be learned from education research and curricular changes in France? Dans E. Dubinsky, A. Schoenfeld, \& J. Kaput, 
Research in collegiate mathematics education (Vol. IV, pp. 1-15). Providence: American mathematical society.

Bagni, G. T. (2005). The historical roots of the limit notion: Cognitive development and development of representation registers. Canadian Journal of Science, Mathematics, and Technology Education, 5(4), 453-468.

Bair, J., \& Henry, V. (2006). Une vision positiviste de nombres hyperréels au moyen d'angles. Liège: École de Gestion de l'Université de Liège.

Bair, J., \& Henry, V. (2008). Analyse infinitésimale : Le calculus redécouvert. Editions Academia.

Barbé, J., Bosch, M., Espinoza, L., \& Gascón, J. (2005). Didactic restrictions on the teacher's practice: the case of limits of functions in Spanish high schools. Educational Studies in Mathematics, 59, 235-268.

Barquero, B., Bosch, M., \& Gascón, J. (2013). The Ecological Dimension in the Teaching of Mathematical Modelling at University. Recherches en Didactique des Mathématiques, $33(3), 307-338$.

Bezuidenhout, J. (2001). Limits and continuity: Some conceptions of first-year students. International Journal of Mathematical Education in Science and Technology, 32(4), 487500.

Bouveresse, J. (1998). Sur le sens du mot «platonisme » dans l'expression « platonisme mathématique ». Conférence du 19 novembre 1998 donnée à l’Université de Genève pour le groupe genevois de la Société romande de philosophie.

Brousseau, G. (1998). Théorie des situations didactiques. Grenoble: La Pensée Sauvage.

Burn, B. (2005). The Vice: Some Historically Inspired and Proof-Generated Steps to Limits of Sequences. Educational Studies in Mathematics, 60(3), 269-295.

Carnot, L. (1797). Oeuvres complètes (Réflexions sur la méthaphysique du calcul infinitésimal). (J. Decker, Éd.) Basle.

Chevallard, Y. (1991). La transposition didactique : du savoir savant au savoir enseigné. Grenoble: La Pensée Sauvage Éditions.

Chevallard, Y. (1999). L'analyse des pratiques enseignantes en théorie anthropologique du didactique. Recherches en Didactique des Mathématiques, 19(2), 221-266.

Chevallard, Y. (2002). Organiser l'étude. 3. Écologie \& régulation. Dans J.-L. Dorier, M. Artaud, M. Artigue, R. Berthelot, \& R. Floris, Actes de la XIe école d'été de didactique des mathématiques (pp. 41-56). Grenoble: La Pensée Sauvage.

Chevallard, Y. (2005). La place des mathématiques vivantes dans l'éducation secondaire. Publication de l'APMEP, 168, 239-263.

Cornu, B. (1991). Limits. Dans D. Tall, Advanced mathematical thinking (pp. 153-166). Dordrecht, Netherlands: Kluwer Academic.

Davis, P., \& Hersch, R. (2012). The Mathematical experience. Birkhäuser.

Dugac, P. (2003). Histoire de l'Analyse. Vuibert.

Edwards, B., \& Ward, M. (2004). Surprises from Mathematics Education Research: Student (Mis)use of Mathematical Definitions. The American Mathematical Monthly, 111(5), 411-424. 
Edwards, C. (1982). The Historical Development of the Calculus. New York: Springer-Verlag.

Fourez, G., Englebert-Lecomte, V., \& Mathy, P. (1997). Nos savoirs sur les savoirs,. Bruxelles: De Boeck.

Freudenthal, H. (1961). The Concept and the Role of the Model in Mathematics and Natural and Social Sciences. Proceedings of the Colloquium Sponsored by the Division of Philosophy of Sciences of the International Union of History and Philosophy of Sciences of the International Union of History and Philosophy of Sciences of the International Union of History and P. Dordrecht: D. Reidel.

Freudenthal, H. (1973). Mathematics as an Educational Task. Springer.

Gantois, J.-Y., \& Schneider, M. (2012). Une forme embryonnaire du concept de dérivée induite par un milieu graphico-cinématique dans une praxéologie ‘modélisation'. Recherches en Didactique des Mathématiques, 32(1), pp. 57-99.

Grabiner, J. (2005). The Origins of Cauchy's Rigorous Calculus. Dover.

Hans, F. (1973). Mathematics as an educational task. Dordrecht: D. Reidel.

Hardy, N. (2009). Students' perceptions of institutional practices: The case of limits of functions in college level Calculus courses. Educational Studies in Mathematics, 72(3), 341-358.

Job, P. (2011). Étude du rapport à la notion de définition comme obstacle à l'acquisition du caractère lakatosien de la notion de limite par la méthodologie des situations fondamentales/adidactiques. Thèse de doctorat: Université de Liège.

Job, P. (2011). Étude du rapport à la notion de définition comme obstacle à l'acquisition du caractère lakatosien de la notion de limite par la méthodologie des situations fondamentales/adidactiques. Thèse de doctorat: Université de Liège.

Job, P. (2014). L'entrée dans les praxéologies déduction. Le cas du concept de limite. Séminaire National de Didactique. Manuscript accepted for publication.

Johsua, S. (1996). Le concept de contrat didactique et l'approche vygotskienne. Dans C. Raisky, \& M. Caillot (Éd.), Au-delà des didactiques, le didactique. Bruxelles: De Boeck université.

Lagrange, J.-L. (1797). Théorie des fonctions analytiques contenant les principes du calcul différentiel dégagés de toute considération d'infiniment petits et d'évanouissans, de limites ou de fluxions et réduits 92. à l'analyse algébrique des quantités finies. Imprimerie de la République.

Lakatos, I. (1976). Proofs and Refutations: The Logic of Mathematical Discovery. Cambridge: Cambridge University Press.

Martinez-Planell, R., Carmen Gonzalez, A. C., \& DiCristina G., A. V. (2012). Students' conception of infinite series. Educational Studies in Mathematics, 81, 235-249.

Monaghan, J. (1991). Problems with the language of limits. For the Learning of Mathematics, $11(3), 20-24$.

Orton, A. (1983). Students' understanding of integration. Educational Studies in Mathematics, 14, $1-18$.

Ostrom, E. (2005). Understanding institutional diversity. Princeton: Princeton University.

Parameswaran, R. (2007). On understanding the notion of limits and infinitesimal quantities. International Journal of Science and Mathematics Education, 5(2), 193 - 216. 
Pétry, A. (2010). Analyse Infinitésimale Une présentation Non Standard. Liège: Éditions du Céfal. Przenioslo, M. (2005). Introducing the Concept of Convergence of a Sequence in Secondary School. Educational Studies in Mathematics, 60(1), 71-93.

Radford, L. (1997). On Psychology, Historical Epistemologyu, and the Teaching of Mathematics : Towards a Socio-Cultural History of Mathematics. For the Learning of Mathematics, 17(1), 26-33.

Rouy, E. (2007). Formation initiale des professeurs de l'enseignement secondaire supérieur et changements de rationalité mathématique entre l'institution secondaire et l'institution universitaire. Le cas éclairant du thème des dérivées. Thèse de doctorat: Université de Liège.

Schneider, M. (1991). Un obstacle épistémologique soulevé par des 'découpages infinis' des surfaces et des solides. Recherches en Didactique des Mathématiques, 11(2.3), pp. 241294.

Schneider, M. (1992). A propos de l'apprentissage du taux de variation instantane. Educational Studies in Mathematics, 23(4), 317-350.

Schneider, M. (2008). Traité de didactique des mathématiques. Liège: Presses Universitaires de Liège.

Sierpinska, A. (1987). Humanities Students and Epistemological Obstacle Related to Limits. Educational Studies in Mathematics(18), 371-397.

Swinyard, C. (2011). Reinventing the formal definition of limit : The case of Amy and Mike. Journal of mathematical Behavior, 30, 93-114.

Tall, D. (1980). Mathematical intuition, with special reference to limiting processes. Proceedings of the fourth International Congress on Mathematics Education. 1, pp. $170-176$. Berkeley.

Tall, D., \& Schwarzenberger, R. (1978). Conflicts in the learning of real numbers and limits. Mathematics Teaching, 82, 44-49.

Tall, D., \& Vinner, S. (1981). Concept image and concept definition in mathematics, with particular reference to limits and continuity. Educational Studies in Mathematics, 12(2), 151-169.

Williams, S. R. (1991). Models of limit held by college calculus students. Journal for Research in Mathematics Education, 22(3), 219-236.

Zandieh, M. (2000). A theoritical framework for analyzing student understanding of the concept of derivative. Dans E. Dubinsky, A. Schoenfeld, \& J. Kaput, Research in collegiate mathematics education IV (pp. 103-127). Providence, RI: American Mathematical Society. 